\title{
Relationship between Decision Making Styles and Life Regrets among Community Dwelling Older Adults
}

\author{
Maha Mohamed El-Sayed Gaafar, Assistant Professor \\ Psychiatric Nursing and Mental Health, Faculty of Nursing, Alexandria University \\ Reham Magdy Mohammed Abd El Salam, Lecturer \\ Gerontological Nursing, Faculty of Nursing, Alexandria University
}

Samia El Husseini Abd El Mageed El Kholy, Lecturer

Gerontological Nursing, Faculty of Nursing, Alexandria University

\begin{abstract}
Older adults have to take several decisions during their life. The older adults' distinctive manner and style of identifying and reacting to decision-making tasks is expected to yield some decision outcomes which may induce feeling of regret. Regret which is a hurting feeling in old age can ultimately impacts the individual's well-being. Objective: Determine the relationship between decision making styles and life regrets among community dwelling older adults. Setting: outpatient clinics of Farouk hospital, affiliated to the Ministry of Health, Alexandria, Egypt. Subjects: 205 older adults. Tools: Three tools were used for data collection: 1) Socio-demographic data structured interview schedule 2) Decision Making Questionnaire DMQ, and 3) Life Regrets Scale. Results: The present study findings showed that the study subjects showed different levels of life regrets which are significantly correlated with the manner they habitually approach and manage their decisions (decision making styles). Conclusion: Greater life regrets among the study subjects were associated with the usage of certain decision making styles such as instinctiveness and social resistance. Whereas, thoroughness, perfectionism and control styles are significantly related to lower life regrets among the study subjects. Recommendations: The gerontological nurses should assess the decision making skills and styles of the older adults. They should assume their role in helping older adults to learn new decision making styles in order to improve their decisions outcomes and prevent future regrets.
\end{abstract}

Keywords: Life regrets; Decision making styles; Older adults; Community dwelling; Gerontological nurse.

\section{Introduction}

Individuals' decisions heavily influence their life circumstances. The consequences of these decisions probably shape individuals well-being ${ }^{(1)}$. The ability to take decisions is an important skill for all ages, and is particularly significant in old age. Older adults face multiple decisions which may have a serious effect on their lives during their remaining years. Often older adults' life conditions are changing as a result of age related changes affecting all body systems. In particularly the brain which is responsible for all decision making, is affected more with ageing process than the other systems. So, older adults' decisions making may be altered and become less effective $^{(2)}$.

Decision outcomes assist in building inferences about the older adults' decision making style ${ }^{(3)}$. Scott \& Bruce (1995) defined decision-making styles as "the learned habitual response pattern exhibited by an individual when confronted with a decision situation" and people are not described by a certain style but by a profile of styles ${ }^{(4)}$.

The theoretical background of variances in decision making styles remains vague $^{(5-7)}$. The number of decision-making styles is subject to debate. Scott and Bruce (1995) proposed five styles of decision ${ }^{(4)}$. 
Among these styles are the rational style which include in deep collection of information and logical appraisal of options, and the intuitive style that rely on intuitions and feelings ${ }^{(8,9)}$. However, Nygren $(2000)^{(10)}$ suggested three decision making styles only. The French's decision making questionnaire (1993) identified seven decision making styles $^{(11)}$. The association between decisionmaking styles and cognitive functions has

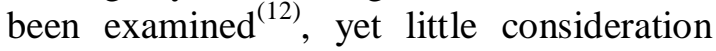
has been given to the relation between decision making styles and actual-life consequences and their predictive power ${ }^{(13)}$.

It has been postulated that not only the resulting events from decision-making, but also how the older adults feel about their decision outcomes is an indicator of realistic decision outcomes. Making numerous decisions throughout life is expected to cause certain decision consequences that may make the older adults unsatisfied ${ }^{(14)}$. Regret, in particular, is commonly experienced as an aversive emotional consequence of incorrect decisions ${ }^{(15)}$. Regret occurs if the selected outcome is, or is thought to be, worse than a non-selected alternative $\mathrm{e}^{(16)}$.

Decision justification theory supposes that, regret feeling after decision making includes outcomes comparison and recognizing responsibility for unjustified decisions $^{(16)}$. However, regret research depends on participants of young age to a great extent ${ }^{(17)}$. Furthermore, it is important to study regret in older age because regret may work in a different manner than it does in younger adults. People of young age may recognize further chances to achieve their goals because they believe that there is extra lifetime available to accomplish these goals $^{(18)}$. Consistent with the theory of socioemotional selectivity, as people become older, they perceive shrinkage of their available time in life ${ }^{(19)}$.

Regret caused by older adults' decision making styles may affect both mental and emotional domains of well-being. Poorer well-being levels were found to be associated with greater regret levels ${ }^{(20)}$. Jokisaari (2004) reported that education and work related regrets affect negatively life satisfaction among older adults ${ }^{(21)}$, while self-related regrets were related to depression in older adults ${ }^{(22)}$. The ability to resolve and overcome regrets is found to contribute to better adults' well-being through ages ${ }^{(20,23)}$.

Older adults may be capable to expect regret $^{(15)}$. So, regret is not only an emotion felt after decisions by the older adults, but it also helps to guide future decisions to avoid further regret. Nurses have to use valid tools to evaluate the degree to which older adults regret their actual life decisions and assess their decision making styles. Nurses should aid older adults in learning and use of new decision making styles known to be related to greater positive outcomes and lesser regrets.

\section{Aim of the Study}

The present study aimed to determine the relationship between decision making styles and life regrets among community dwelling older adults.

\section{Research Question:}

What is the relationship between decision making styles and life regrets among community dwelling older adults?

\section{Materials and Method}

\section{Materials}

Design: The study followed a descriptive correlational research design.

Setting: The study was carried out at Farouk hospital outpatient clinics, affiliated to the Ministry of Health, Alexandria, Egypt. The hospital comprises several outpatient clinics that include different specialties such as; dentition, ophthalmology, and diabetic clinics. The clinics work from Saturday to Thursday from 9 am to $12 \mathrm{pm}$. 
Subjects: The study included 205 older adults who fulfill the following inclusion criteria:

- Age 60 years and more

- Able to communicate effectively

- Accept to participate in the study

- Available at the selected setting during the period of data collection

The sample size was estimated using the EPI info 7.0 program based on these parameters; population size: 400, possible error $5 \%$, confidence coefficient $95 \%$, and minimal sample size 180 .

Tools: Three tools were used in the study to collect the necessary data as follows:

\section{Tool I: Socio-demographic data structured interview schedule}

This tool was developed by the researchers to determine the sociodemographic features of the study subjects such as age, sex, level of education, marital status and self-rating health.

\section{Tool II: Decision Making Questionnaire (DMQ)}

This is a 21 items tool developed by French et al, $1993^{(11)}$ to assess the decision making styles. This questionnaire comprises seven decision making styles namely;

1. Thoroughness (4 items): extremely attentive to accuracy, plans, and details and follow a logical process of thinking and predicting outcomes of their actions and decisions.

2. Control (5 items): able to maintain emotional stability and think properly during stress.

3. Hesitancy (3 items): being undecided and if the older adult reaches a certain solution, they shift to another.

4. Social resistance (3 items): refuse consulting others or taking advices from them.
5. Perfectionism (2 items): try to reach the best among the alternatives.

6. Idealism (2 items): follow the principles and ideals regardless of their applicability in their environment.

7. Instinctiveness (2 items): depend on mainly on emotions rather than ideas.

Older adults indicated how often each statement applied to them, infrequently or never $=1$, quite frequently $=2$, frequently $=3$. The score is reversed for negative items. Higher mean percent score in each decision making style indicates increased frequency of using this style by older adults.

\section{Tool III: Life Regrets Scale}

Life regrets scale is a single-factor tool that developed by Pethtel, et al. $2012^{(1)}$ in order to evaluate the degree to which participants feel regret for events that they have experienced in the past. Older adults rated 9 items on a 5-point Likert scale (e.g. Looking back on their life, how much do they regret decisions that they have taken and affected their finances, education, family relation, social relationship outside the family, health, work (or their role for unemployed elders), leisure time, and the way they handled their self, and regret about wrong decisions in life. Older adults indicated the degree to which they regret each item (no regret=1, slightly regret $=2$, moderately regret $=3$, strongly regret $=4$, very strongly regret $=5$ ). Scores are represented by mean percent, with higher scores showing very intense life regrets.

Statistically, the researchers classified the total score of this scale into five levels of life regrets as follows;

$\begin{array}{lll}\text { - } & \text { No regret: } & 1-9 \\ \text { - } & \text { Mild regret: } & 10-18 \\ \text { - } & \text { Moderate regret: } & 19-27 \\ \text { - } & \text { Severe regret: } & 28-36 \\ \text { - } & \text { Very severe regret: } & 37-45\end{array}$




\section{Method}

- Permission to carry out the study from the responsible authorities of the Faculty of Nursing, Alexandria University was obtained.

- A letter was issued from the Faculty of Nursing, Alexandria University to the director of the study setting to obtain his approval for data collection.

- The responsible authorities of the study setting were informed about the purpose of the study, the date and time of data collection.

- Tool I was developed by the researchers to assess the sociodemographic data of the study subjects

- Tool II, and tool III were translated into Arabic language by the researchers. Tool II, and tool III were tested for content validity by three experts in the study field.

- Tool II, and tool III were tested for reliability. The result of Cronbach's Coefficient alpha was 0.77 for tool II and 0.81 for tool III.

- A pilot study was carried out on 25 older adults selected from the study setting. They were not included in the study sample. The pilot study was done to assess the applicability and clarity of the tools.

- Older adults who fulfill the inclusion criteria were interviewed by the researchers individually in the waiting area in the outpatient clinics to collect the necessary data after clarification of the study purpose.

\section{Ethical considerations:}

Informed witness consent was obtained from each study subject after clarification of the study purpose. Anonymity and privacy of the study subjects were maintained. Confidentiality of the collected data and the subject's right to withdraw at any time from the study were assured.

\section{Statistical Analysis}

Data collected were analyzed by computer using the Statistical Package for Social Sciences (SPSS) software version 20. Reliability of the tools was determined by Cronbach Coefficient alpha. Data were presented by descriptive statistics in the form of frequencies and percentages for qualitative variables, and arithmetic mean, mean percent and standard deviation for quantitative variables. Pearson Correlation Coefficient was used for testing relationship between variables. Significant difference was considered if $\mathrm{p} \leq 0.05$.

\section{Results}

Table (1) shows the socio-demographic data of the study subjects. Their mean age is $64.35 \pm 5.22$ years, $73.7 \%$ are females, $66.8 \%$ married, and $53.7 \%$ are illiterate. A small percent, $12.2 \%$, completed their secondary school education and only $9.8 \%$ had university degree. Housewives constituted $52.7 \%$ of the study subjects and the rest were employee $22.4 \%$, skilled workers $13.7 \%$, or unskilled workers $11.2 \%$. Study subjects who are current workers constitute $15.1 \%$ of the sample. Monthly income is reported to be inadequate by $74.6 \%$ of the study subjects. Also, $61.0 \%$ live in urban and $89.3 \%$ live with their family. Only $11.8 \%$ of the study subjects rated their health as very good and $37.6 \%$ reported poor self-rating health.

Table (2) illustrates that only $2.9 \%$ of the study subjects reported no feeling of life regrets, while, mild, moderate, severe, and very severe life regrets are reported by $16.6 \%, \quad 50.7 \%, \quad 27.3 \%$ and $2.4 \%$ respectively. The mean percent score of life regrets is $42.56 \pm 19.50$.

Table (3) shows the main types of regrets among the study subjects. The greater mean percent score of life regrets is related to the way they deal with themselves $81.71 \pm 35.11$ followed by the regret about making wrong choices generally in their past life 68.66 \pm 37.74 , health related regret 
$65.61 \pm 38.27$, and education related regret $63.29 \pm 44.32$. The lowest mean percent of life regrets among the study subjects is related to the way they pursued their leisure $12.07 \pm 27.52$.

Table (4) indicates the mean percent scores of decision making styles as adopted by the study subjects as follows; idealism $77.93 \pm 35.06$ followed by thoroughness $56.16 \pm 28.70$, hesitancy $51.63 \pm 29.43$, and instinctiveness $48.41 \pm 31.81$. Control style of decision making is the lesser used style by the study subjects $35.80 \pm 34.26$.

Table (5) shows significant positive relations between adoption of certain decisions making styles as instinctiveness and social resistance styles and greater life regrets among the study subjects, $r=0.201$, $\mathrm{p}=0.004, \mathrm{r}=0.158, \mathrm{p}=0.024$ respectively. $\mathrm{On}$ the other hand, use of other decision making styles as thoroughness, perfectionism and control by the study subjects is significantly related to lower life regrets, $(\mathrm{r}=-0.190$, $\mathrm{p}=0.006),(\mathrm{r}=-0.270, \mathrm{p}<0.001),(\mathrm{r}=-0.393$, $\mathrm{p}<0.001)$ respectively.

\section{Discussion}

Understanding how and why older adults experience regret and how their choices and decision making styles influence their feeling of regret are important research questions. While, earlier researches focused mainly on participants of young age ${ }^{(17)}$, this study aimed to determine the relationship between decision making styles and life regrets among community dwelling older adults.

With reference to the relationship between decision making styles and life regrets among the study subjects, the present study results reveal that use of social resistance and instinctiveness styles of decision making are significantly associated with higher life regrets among the study subjects (table 5). This result may be due to that, the study subjects may underestimate their friend's abilities as decision makers. For example, their friends and social network around them may be within the same level of education, occupation and low decision making competencies. So, they avoid consulting them or accepting their advices due to expected or actual negative outcome of their solutions. Indeed, the study subjects may adopt this style of decision making due to their fear from disclosure of their problems and secrets in front of others. As a result, they may deprive themselves from the benefits of others' experiences and the attempts of people who experienced similar situations. In this respect, Geisler et al. (2017) reported the significant role of social network on shaping the individuals' decision making style and their feeling of regret $^{(7)}$.

Also, in using the instinctiveness style, the study subjects may depend on their internal feelings to determine what to do. Most of time, the internal emotions depend on no logical evidence or process. These emotions may affect their way of decision making especially if their decisions are related to their children or to those whom they love and care. So, the outcome can't be controlled when it depends only on feelings. Later on, study subjects might regret the decisions they made. Several researches postulated the significant role of emotion in decision making outcomes ${ }^{(24,25)}$.

Regarding the use of thoroughness, perfectionism, or control styles of decision making, these were found to be significantly and negatively related to life regrets among the study subjects (table 5). The present study results can be explained by the fact that study subjects who use the thoroughness style of decisions making will follow a sequence of logical process of thinking during assessing the stressful situations and then determine the available choices and their consequences. After that, they select the appropriate one. So, later on, life regrets would be less. The present study results are in accordance with what was reported by other researches which indicated that in thoroughness style of decision making, older adults become more thoughtful and less risk 
taking. Moreover, they are usually satisfied with their decision outcomes ${ }^{(26,27)}$.

Regarding perfectionism style, the study subjects who adopted this style may seek the best decisions and will not be satisfied with only the available solutions or choose the first easiest one. But, they will search for the best or other solutions for their problems. It was reported by other authors that older adults who use the perfectionism style are better qualified individuals and they are able to solve difficult problems ${ }^{(3,5)}$.

With reference to control style of decision making, it may help the study subjects to be calmer during stressful situations, to think logically while searching for solutions, and to take free choices with little chances of faults or poor outcomes. The present study result supports what was reported by Hashimoto et al. (2004) ${ }^{(28)}$. Zeelenberg et al. (2016) reported correlations between different decision making styles and life regrets ${ }^{(29)}$.

The present study result reveals that most of the study subjects feel some degree of life regrets varying from mild to very severe life regrets (table 2). The present study result may be due to the poor economic, educational and occupational status of the study subjects which limit the available choices for the individuals and the chance to have volunteer independent decisions is usually diminished. Study subjects may usually select the safest solution avoiding the risk for another solution even if it seemed to be the best. The present study result support many other researches which indicated that regret is systematically related to aging ${ }^{(30-32)}$. Choi NG and Jun J (2009) revealed that regret in old age is associated with inadequate monthly income ${ }^{(33)}$. Also, education, and occupational status were found to be correlated with feeling of regret as reported by Lecci et al. (2004) ${ }^{(34)}$. Moreover, study subjects with unsatisfying socioeconomic status may be mainly present oriented not future oriented and have no plan to achieve their goals or hobbies. They just satisfy their present needs. With time, they found that they didn't achieve their goals or dreams and their regrets would be greater. Giloviqh et al. (2005) revealed that the decision making is a complex and conflict process. With a lot of needs to be met, older adults determine their priorities to meet their needs, so, regret for having made wrong choices are challenging $^{(35)}$.

Regarding the main types of life regrets among the study subjects, the present study finding shows that they regret mainly the way they handled themselves, making wrong decisions in their life, and the decisions they did concerning their health and education (table 3 ). This can be justified by that inadequate economic status may make the older adults especially females to devote all of their efforts and energy to satisfy the needs of their husband's and children's and neglecting their own needs. Sometimes they may postpone meeting of their needs until their economic conditions may be improved in the future. They might neglect their rights to live independently, to have recreational activities, to have follow up for their health or to get enough educational chances due to their poor economics. So, later on, they may regret decisions they made regarding these selfbasic needs. The present study finding is supported by what was reported by other researches which indicated that the main life events regrets are related to occupation, education, social relationships, self-right, finance, and health ${ }^{(17,18,36)}$.

With reference to the main decisions making styles adopted by the study subject, the present study result reveals that these styles are idealism followed by thoroughness and hesitancy (table 4). Style of idealism may be the main decision making style among the study subjects due to the nature of the Egyptian culture which implies rules, regulations, traditions, norms and religion that control the individual's behaviors, thoughts and decisions. Among these culture items is the obligation to follow the agreed 
and known principles and what is right regardless the outcome of the action and regardless the reactions of those who are involved in the situations.

Concerning thoroughness decision making style, study subjects may depend on a logical process in their decision making to limit the draw backs of their decisions especially if the available alternatives are usually limited. Also, hesitancy style may be adopted by the study subjects and being undecided due to their possible fears from leaving outside the area of stability and comfort to make new action which carry unknown results. Moreover, the present study result indicates that the control style of decision making is the lesser one adopted by the study subjects. This may be due to several losses in old age which might harm the study subjects' internal locus of control causing them to lose their decision making power to some extent in the stressful situations. It was suggested by several authors that decision making in old age mainly involves logical process of thinking as in thoroughness style through selecting the choice that is most expected to meet their aims by thinking through the available alternatives and comparing all the options $^{(37,38)}$.

\section{Conclusion}

Based on the present study results, it can be concluded that the way the study subjects habitually approach and manage their decisions are significantly related to their life regrets. More specifically, the present study results indicated that study subjects who reported use of instinctiveness and social resistance as decisions making styles have significant greater overall life regrets. On the other hand, other decision making styles as thoroughness, perfectionism and control are significantly related to lower life regrets among the study subjects.

\section{Recommendations}

Based on the findings of the present study, the following recommendations are suggested:

- Nurses who are caring for older adults should determine how older adults' decision making styles differ among them. It may help in planning suitable information and decision aids to each older adults.

- Nurses can help older adults in predicting and preventing future regret through correctly managing decision making situations and learning effective decision making styles.

- Nurses should carry out thorough history of older adults to determine those who are suffering from regret and identify its possible causes and consequences on their current health and wellbeing.

- Nurses have the responsibility to assist older adults to manage their feeling of regret to limit its negative outcomes.

\section{The future researches in this field could include:}

- Studies are needed to determine the effect of nursing interventions for enhancing decision making competencies and styles on psychosocial wellbeing among older adults. 
Table (1): Distribution of the study subjects according to their socio-demographic data

\begin{tabular}{|c|c|c|}
\hline Socio-demographic data & No. $=205$ & Frequency \% \\
\hline $\begin{array}{l}\text { Age (in years) } \\
>70 \\
70-80 \\
80 \text { years and more }\end{array}$ & $\begin{array}{c}168 \\
32 \\
5\end{array}$ & $\begin{array}{l}82.0 \\
15.6 \\
2.4\end{array}$ \\
\hline $\begin{array}{l}\text { Sex } \\
\text { Male } \\
\text { Female }\end{array}$ & $\begin{array}{c}54 \\
151\end{array}$ & $\begin{array}{l}26.3 \\
73.7\end{array}$ \\
\hline Mean \pm SD. & \multicolumn{2}{|c|}{$64.35 \pm 5.22$} \\
\hline $\begin{array}{l}\text { Social status } \\
\text { Married } \\
\text { Widow } \\
\text { Single }\end{array}$ & $\begin{array}{c}137 \\
60 \\
8\end{array}$ & $\begin{array}{c}66.8 \\
29.3 \\
3.9\end{array}$ \\
\hline $\begin{array}{l}\text { Educational level } \\
\text { Illiterate } \\
\text { Basic education } \\
\text { Secondary education } \\
\text { University education }\end{array}$ & $\begin{array}{l}110 \\
50 \\
25 \\
20\end{array}$ & $\begin{array}{c}53.7 \\
24.3 \\
12.2 \\
9.8\end{array}$ \\
\hline $\begin{array}{l}\text { Work prior to retirement } \\
\text { Employee } \\
\text { Housewife } \\
\text { Skilled worker } \\
\text { Unskilled worker }\end{array}$ & $\begin{array}{c}46 \\
108 \\
28 \\
23\end{array}$ & $\begin{array}{l}22.4 \\
52.7 \\
13.7 \\
11.2\end{array}$ \\
\hline $\begin{array}{l}\text { Current work status } \\
\text { Yes } \\
\text { No }\end{array}$ & $\begin{array}{c}31 \\
174\end{array}$ & $\begin{array}{l}15.1 \\
84.9\end{array}$ \\
\hline $\begin{array}{l}\text { Monthly income } \\
\text { Enough } \\
\text { Not enough }\end{array}$ & $\begin{array}{c}52 \\
153\end{array}$ & $\begin{array}{l}25.4 \\
74.6\end{array}$ \\
\hline $\begin{array}{l}\text { Place of Resistance } \\
\text { Urban } \\
\text { Rural }\end{array}$ & $\begin{array}{c}125 \\
80\end{array}$ & $\begin{array}{l}61.0 \\
39.0\end{array}$ \\
\hline $\begin{array}{l}\text { Living style } \\
\text { With family } \\
\text { Alone }\end{array}$ & $\begin{array}{c}183 \\
22\end{array}$ & $\begin{array}{l}89.3 \\
10.7\end{array}$ \\
\hline $\begin{array}{l}\text { Self-rating health } \\
\text { Very good } \\
\text { Good } \\
\text { Faire } \\
\text { Poor }\end{array}$ & $\begin{array}{l}24 \\
57 \\
47 \\
77\end{array}$ & $\begin{array}{l}11.8 \\
27.8 \\
22.9 \\
37.6\end{array}$ \\
\hline
\end{tabular}


Table (2): Distribution of the study subjects according to their levels of life regret

\begin{tabular}{|c|c|c|}
\hline Levels of life regret & No. $=\mathbf{2 0 5}$ & Frequency (\%) \\
\hline - No regret & 6 & 2.9 \\
\hline - $\quad$ Mild regret & 34 & 16.6 \\
\hline - $\quad$ Moderate & 104 & 50.7 \\
\hline - Severe regret & 56 & 27.3 \\
\hline - $\quad$ Very severe regret & 5 & 2.4 \\
\hline Mean \pm SD $\%$. & \multicolumn{2}{|c|}{$42.56 \pm 19.50$} \\
\hline
\end{tabular}

Mean $\pm S D \%$ : mean percent score

Table (3): Distribution of the study subjects according to their types of life regrets

\begin{tabular}{|c|c|c|}
\hline Types of life regrets & Mean \pm SD. & "Mean \pm SD\%. \\
\hline - Oneself & $4.27 \pm 1.40$ & $81.71 \pm 35.11$ \\
\hline - Wrong decisions in general & $3.75 \pm 1.51$ & $68.66 \pm 37.74$ \\
\hline - $\quad$ Health & $3.62 \pm 1.53$ & $65.61 \pm 38.27$ \\
\hline - Education & $3.53 \pm 1.77$ & $63.29 \pm 44.32$ \\
\hline - Work $\backslash$ role & $2.24 \pm 1.38$ & $31.10 \pm 34.38$ \\
\hline - Family relation & $2.09 \pm 1.39$ & $27.32 \pm 34.71$ \\
\hline - Finance & $1.75 \pm 1.06$ & $18.66 \pm 26.59$ \\
\hline $\begin{array}{l}\text { - Social relation outside } \\
\text { family }\end{array}$ & $1.59 \pm 1.10$ & $14.63 \pm 27.55$ \\
\hline - Leisure time & $1.48 \pm 1.10$ & $12.07 \pm 27.52$ \\
\hline
\end{tabular}

Mean $\pm S D \% .:$ mean percent score 
Table (4): Distribution of the study subjects according to their decision making styles $(\mathrm{n}=\mathbf{2 0 5})$

\begin{tabular}{|c|c|c|}
\hline \multirow{2}{*}{ Decision making styles } & Total score & Mean percent score \\
\hline & Mean \pm SD. & Mean \pm SD \% \\
\hline - Idealism & $5.12 \pm 1.40$ & $77.93 \pm 35.06$ \\
\hline - $\quad$ Thoroughness & $8.49 \pm 2.30$ & $56.16 \pm 28.70$ \\
\hline - Hesitancy & $6.10 \pm 1.77$ & $51.63 \pm 29.43$ \\
\hline - $\quad$ Instinctiveness & $3.94 \pm 1.27$ & $48.41 \pm 31.81$ \\
\hline - Social resistance & $5.51 \pm 2.11$ & $41.87 \pm 35.11$ \\
\hline - $\quad$ Perfectionism & $3.54 \pm 1.61$ & $38.41 \pm 40.26$ \\
\hline - Control & $8.58 \pm 3.43$ & $35.80 \pm 34.26$ \\
\hline
\end{tabular}

Mean $\pm S D \%$ : mean percent score

Table (5): Relationship between decision making styles and life regrets among the study subjects

\begin{tabular}{||l|c|c||}
\hline \multirow{2}{*}{ Decision making styles } & \multicolumn{2}{|c||}{ Life regrets } \\
\cline { 2 - 3 } & $\mathbf{R}$ & P \\
\hline 1- Instinctiveness & $0.201^{*}$ & $0.004^{*}$ \\
\hline 2- Thoroughness & $-0.190^{*}$ & $0.006^{*}$ \\
\hline 3- Idealism & 0.049 & 0.486 \\
\hline 4- Perfectionism & $-0.270^{*}$ & $<0.001^{*}$ \\
\hline 5- Hesitancy & -0.020 & $0.781^{*}$ \\
\hline 6- Social resistance & $0.158^{*}$ & $0.024^{*}$ \\
\hline 7- Control & $-0.393^{*}$ & $<0.001^{*}$ \\
\hline
\end{tabular}

r: Pearson coefficient $\quad$ *: Statistically significant at $p \leq 0.05$ 


\section{References}

1. Pethtel O. Decision-Making Competence, Life Regrets, and Subjective Well-Being in Mature Adults. Published Doctoral Dissertation, Ohio: Bowling Green State University, 2012.

2. Mather M. Decision-Making Processes: Weighing the Risks and Benefits of Aging. New York: Oxford University Press; 2006.

3. Bruine de Bruin W, Parker A.W, Fischhoff B. Individual differences in adult decisionmaking competence. Journal of Personality and Social Psychology. 2007; 92(5):93856.

4. Scott S. G, Bruce R. A. Decision-making style: The development and assessment of a new measure. Educational and Psychological Measurement J. 1995; 55(5):818-31.

5. Appelt K. C, Milch K. F, Handgraaf M. J, Weber E. U. The Decision Making Individual Differences Inventory and guidelines for the study of individual differences in judgment and decisionmaking research. Judgment and Decision making J.2011; 6(3): 252-62.

6. Mohammed S, Schwall A. Individual differences and decision making: What we know and where we go from here. International review of industrial and organizational psychology J. 2009; 24: 249-312.

7. Geisler M, Allwood C. M. Relating Decision-Making Styles to Social Orientation and Time Approach. Behav. Dec. Making J. 2017; 4: 430-41.

8. Allwood C. M, Salo I. Decision-making styles and stress. International Journal of Stress Management. 2012; 19: 34-47.

9. Cheng Mau W. Decision-Making Style as a Predictor of Career Decision-Making Status and Treatment Gains. Career assessment J. 1995; 3:66-82. Journal of Career Assessment

10. Nygren T. E. Development of a measure of decision making styles to predict performance in a dynamic decision making task. Current Directions in Psychological Science J. 2000; 41: 352-66.
11. French D.J, West R. J, Elander J, Wilding J.M. Decision-Making Style, Driving Style, And Self-Reported Involvement In Road Traffic Accidents. International Journal of Methods in Psychiatric Research. 1993; 36(6): 627-44.

12. Salo I, Alwood M. Decision-making styles, stress and gender among investigators. International Journal of Police Strategies \& Management. 2011; 34: 97-119.

13. Galotti K. M, Ciner E, Altenbaumer H. E, Geerts H. J, Rupp A, Woulfe J. Decisionmaking styles in a real-life decision. Judgment and Decision Making J. 2006; 41(4): 629-39.

14. Hastie R, Dawes R.M. Rational choice in an uncertain world: The Psychology of judgment and decision making. Journal of Behavioral and Experimental Economics. 2001; 2:275-86.

15. Zeelenberg M, Pieters R. A theory of regret regulation. Consumer Psychology J. 2007; 17: 3-18.

16. Connolly T, Zeelenberg M. Regret and decision making. Current Directions in Psychological Science. Psychological association J .2002; 11(6): 212-16.

17. Peters E, Västfjäll D, Slovic P, Mertz C.K, Mazzocco K, Dickert S. The Experience and Regulation of Regret across the Adult Life Span. Psychological association J. 2011; 17(5): 165: 80.

18. Pethtel O, Chen Y. Life regrets and life satisfaction in mature adults. The Journal of Happiness \& Well-Being. 2014; 2(2): 10618.

19. Carstensen L. The influence of a sense of time on human development. Human Science J.2006; 312: 1913-15.

20. Dijkstra P, Barelds D. What Dutch women of different ages regret. Journal of Research in Personalit.2008; 42: 1663-7.

21. Jokisaari M. Regrets and Subjective WellBeing: A Life Course Approach. Journal of Adult Development. 2004; 11(4): 281-8. 
22. Wrosch C, Bauer I, Scheier M. Regret and quality of life across the adult life span: The influence of disengagement and available future goals. Psychology and Aging J. 2005; 20: 657-70.

23. Torges CM, Stewart A.J, Hoeksema S. Regret resolution, aging, and adapting to loss. Psychology and Aging J. 2008; 23:169-80.

24. Schwarz N. Emotion, cognition, and decision making. Cognition and Emotion J.2010; 14(4): 433-40.

25. Angie AD, Connelly S, Waples EP, Kligyte $\mathrm{V}$. The influence of discrete emotions on judgement and decision-making: A metaanalytic review. Cognition \& Emotion J. 2011; 25(8): 1393-422.

26. Driver M.J, Mock T.J. Human Information Processing, Decision Style Theory, and Accounting Information Systems. American Accounting Association J. 2005; 50(3): 490-508

27. Shane F. Cognitive Reflection and Decision Making. Journal of Economic Perspectives. 2005; 19(4): 25-42.

28. Hashimoto H, Fukuhara S. The influence of locus of control on preferences for information and decision making. Patient Educ Couns J. 2004; 55(2):236-40.

29. Zeelenberg M, Beattie J, Pligt J, Vries N. Consequences of Regret Aversion: Effects of Expected Feedback on Risky Decision Making. Organizational Behavior and Human Decision Processes J.2016; 65(2): 148-58.

30. Wrosch C, Heckhausen J. Perceived control of life regrets: Good for young and bad for old adults. Psychology and Aging J. 2002; 17: 340-50.

31. Wurm L. H, Labouvie-Vief G, Aycock J, Rebucal K. A, Koch H. E. Performance in auditory and emotional Stroop tasks: A comparison of older and younger adults. Psychology and Aging J. 2004; 19: 523-35.

32. Zeelenberg M. Anticipated regret, expected feedback and behavioral decision-making. Journal of Behavioral Decision Making.2007; 12: 93-106.
33. Choi NG, Jun J. Life regrets and pride among low-income older adults: relationships with depressive symptoms, current life stressors and coping resources. Aging Ment Health J .2009; 13(2): 213-25

34. Lecci L, Okun M. A, Karoly P. Life regrets and current goals as predictors of psychological adjustment. Journal of Personality and Social Psychology.2004; 66: $731-41$.

35. Giloviqh T, Medvec V.H. The Experience of Regret: What, When, and Why. American Psychological Association J. 2005; 102(2): 379-95.

36. Othelia EL, Seungah R. Content and Intensity of Pride and Regret among Asian American Immigrant Elders. International Journal of Aging and Human Development. 2017; 25(4):105- 25.

37. Carpenter S.M, Yoon C. Aging and Decision Making; Empirical and Applied Perspectives. Aging Ment Health J. 2015; 3: 351-70

38. Yoon C, Cole C.A, Lee M.P. Consumer decision making and aging: Current knowledge and future directions. Consumer Psychology J. 2009; 19: 2-16. 